\title{
Endophytic establishment of Beauveria bassiana and Metarhizium anisopliae in maize plants and its effect against Spodoptera frugiperda (J. E. Smith) (Lepidoptera: Noctuidae) larvae
}

\author{
Yordanys Ramos ${ }^{1 *}$ (D, Alberto Daniel Taibo', Jorge Ariel Jiménez ${ }^{1}$ and Orelvis Portal ${ }^{2,3}$
}

\begin{abstract}
The aim of the present study was to evaluate the artificial establishment of Beauveria bassiana and Metarhizium anisopliae as endophytes in maize plants, and its effect in controlling the fall armyworm, Spodoptera frugiperda (J. E. Smith) (Lepidoptera: Noctuidae) larvae. The commercial strains B. bassiana Bb-18 and M. anisopliae Ma-30 were concentrated at $1 \times 10^{8}$ conidia $\mathrm{ml}^{-1}$, and the soil drench method was used to establish them as endophytes in maize plant parts. The biological control assays were conducted under laboratory conditions on second and fourth larval instars of S. frugiperda. B. bassiana colonized roots, stems, and leaves of maize tissues. However, a high occurrence of $B$. bassiana was obtained in roots than leaves and stems with 25, 10, and 5 isolations, respectively, whereas M. anisopliae was only acquired on roots. Both entomopathogenic fungi caused (100\%) mortality on the second instar larvae. In addition, B. bassiana and M. anisopliae killed (87 and 75\%) of the fourth larval instars, respectively. The fungus $M$. anisopliae caused the highest sporulation rates during the study. These results suggest that the entomopathogenic fungi might contribute to a sustainable $S$. frugiperda management in maize production in Cuba.
\end{abstract}

Keywords: Biological control, Endophytes, Entomopathogenic fungi, Spodoptera frugiperda, Maize

\section{Background}

The fall armyworm, Spodoptera frugiperda (J. E. Smith) (Lepidoptera: Noctuidae), is distributed in tropical and subtropical regions (Pogue 2002). This insect pest causes damage to several host plants (maize, peanuts, cotton, soybean, and forage grasses); however, the maize (Zea mays L.) constitutes the main agricultural crop preferred by $S$. frugiperda (Virla et al. 2008). The most serious damage produced by this pest is continuous consumption of the young shoots reducing the photosynthetic area of the plant.

\footnotetext{
*Correspondence: ramosg@uclv.edu.cu

'Departamento de Agronomía, Universidad Central "Marta Abreu" de Las

Villas, Carretera a Camajuaní km 5.5, 54830 Santa Clara, CP, Cuba

Full list of author information is available at the end of the article
}

Currently, the most employed method to reduce populations of $S$. frugiperda is the spraying of chemical insecticides, but despite its fast mode of action, the larvae have developed resistance as effects of this method of control, and it causes environmental pollution (Berón and Salerno 2006). Furthermore, S. frugiperda larvae remain feeding inside the plant shoots reducing the contact with insecticides applied for their control (Braga Maia et al. 2013). For these reasons, the use of biological control as an ecofriendly alternative could be effective to control S. frugiperda. Among the most biological control measures used stand out the entomopathogenic fungi (EPF); Beauveria bassiana (Balsamo-Crivelli) Vuillemin, and Metarhizium anisopliae (Metschnikoff) Sorokin, because they can cause 
infection at all life stages (Hajek and St Leger 1994). These EPF can also act as saprophytes on the organic matter and live as endophytes of several plants (Vega 2008). However, the endophytic colonization by EPF might be more widespread than currently realized and may provide a source of indirect interaction between fungi and insects. Furthermore, studies related to the endophytic colonization of $B$. bassiana and M. anisopliae in maize in Cuba and its use as biological control on S. frugiperda is already scarce.

The aims of this study were therefore to evaluate the artificial establishment of B. bassiana and M. anisopliae as endophytes in maize plants, and their effect in controlling S. frugiperda larvae.

\section{Material and methods}

\section{Experimental setup and soil treatment}

The experiment was carried out at the laboratory of Microbiology belonged to Universidad Central "Marta

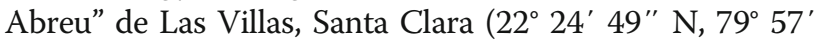
$\left.58^{\prime \prime} \mathrm{W}\right)$, Cuba. Twenty kilograms of an Inceptisol soil (USDA Soil Taxonomy) were collected from an agroecological maize field located in "Encrucijada" municipality $\left(22^{\circ} 37^{\prime} 01^{\prime \prime} \mathrm{N}, 79^{\circ} 51^{\prime} 58^{\prime \prime} \mathrm{W}\right)$. The soil was autoclaved 3 times at $121{ }^{\circ} \mathrm{C}$ for $1 \mathrm{~h}$. The efficacy of the sterilization was evaluated by diluting $1 \mathrm{~g}$ of soil in $20 \mathrm{ml}$ sterile distilled water and then by inoculating $100 \mu \mathrm{l}$ (soil + water solution) on Sabouraud Dextrose Agar (SDA) culture medium without antibiotics. Petri dishes $(9 \mathrm{~cm}$ diameter) with the soil inoculations were incubated at $25{ }^{\circ} \mathrm{C}$ and $75 \%$ relative humidity $(\mathrm{RH})$ in the dark. Effectiveness of the soil sterilization was reached when no growth of bacterial or fungal microorganisms were detected.

\section{Endophytic colonization of B. bassiana and M. anisopliae on maize plants}

The EPF used in the study were the commercial strains B. bassiana Bb-18 and M. anisopliae Ma-30. These fungi were previously isolated from Hypothenemus hampei Ferrari and stored at the EPF collection of the Facultad de Ciencias Agropecuarias, Universidad Central "Marta Abreu" de Las Villas. Sterile soil was deposited into 40 polyethylene bags (500 g capacity), and then 20 bags were inoculated with $10 \mathrm{ml}$ of the commercial strain of $B$. bassiana $\mathrm{Bb}-18$, and the other 20 bags were inoculated with $10 \mathrm{ml}$ of $M$. anisopliae Ma-30 at a concentration of $1 \times 10^{8}$ conidia $\mathrm{ml}^{-1}$. The soil contained into the bags was incubated during 7 days in a climatic chamber (Memmert, Germany) at $25{ }^{\circ} \mathrm{C}$ and $75 \% \mathrm{RH}$ in the dark to propitiate the establishment of the entomopathogenic fungi. Afterwards, maize grains cv ' $\mathrm{P} 78-45$ ' were sown into the soil contained in the bags at a ratio of 1 grain per bag, and then the bags were placed into a germination chamber (TP, China) at $25{ }^{\circ} \mathrm{C}, 75 \% \mathrm{RH}$, and $16 \mathrm{~h}$ of light and $8 \mathrm{~h}$ of dark (L16:D8). Once the maize plants reached the growth stage $\mathrm{BBCH} 12$ (2 leaves unfolded) (Meier 2001), roots, stems, and leaves were collected and surface sterilized by dipping for $3 \mathrm{~min}$ in $1.5 \%$ sodium hypochlorite, $2 \mathrm{~min}$ in $70 \%$ ethanol, and then rinsed 3 times in sterile distilled water. The efficacy of sterilization was evaluated by inoculating $100 \mu \mathrm{l}$ of the last rinse water on SDA culture medium.

Damaged plants resulting from the sterilization procedure were discarded to avoid the death of the endophyte tissue (Douglas et al. 2012). Afterwards, plants were dried by sterile paper towels and aseptically cut into small pieces (1 $\mathrm{cm}^{2}$ ) in a laminar flow hood. The plant pieces were then inoculated on SDA culture medium contained in Petri dishes (9 $\mathrm{cm}$ diameter) with addition of chloramphenicol (250 $\mathrm{mg} / \mathrm{l} \mathrm{w} / \mathrm{v})$. The Petri dishes with the plant pieces were incubated before. A single spore of each EPF was harvested and re-inoculated on SDA culture medium to obtain colonies without contamination. For each EPF studied, 4 replications were done.

\section{Insects assay}

Both EPF strains, B. bassiana Bb-18 and M. anisopliae Ma-30, were supplied by the Plant Health Center from Villa Clara province. Conidia of each fungal strain were adjusted to a final concentration of $1 \times 10^{8}$ conidia $\mathrm{ml}^{-1}$ through a Neubauer hemocytometer chamber (Brand, Germany). The EPF were diluted in distilled water. Additionally, distilled water was used as the control treatment. To evaluate the effect of each fungal formulation against $S$. frugiperda, a pedigree of this insect was obtained under laboratory conditions (Chacón-Castro et al. 2009). Twenty larvae from the second instar of $S$. frugiperda and 20 from the fourth instar were dipped for 1 min into $15 \mathrm{ml}$ of a conidial suspension of $B$. bassiana $\mathrm{Bb}-18$ and M. anisopliae Ma-30, as well as $15 \mathrm{ml}$ of distilled water (control treatment). After $10 \mathrm{~min}$ of treatments exposure, each larva was placed individually in a sterile Petri dish $(15 \mathrm{~cm}$ diameter) with a portion of leaves and stem of maize plants (growth stage $\mathrm{BBCH} 12$ ) for feeding. Petri dishes with $S$. frugiperda were incubated at $25^{\circ} \mathrm{C}, 90 \% \mathrm{RH}$, and L16:D8 photoperiod. Larvae were checked every day for mortality and production of mycosis. The experiment was repeated 4 times, and for each treatment 4 replications were used.

\section{Data analysis}

Data on frequencies of occurrence of endophytic $B$. bassiana and $M$. anisopliae in maize plant parts were analyzed by chi-square test. Chi-square statistics were calculated through a frequency table, and $p$ values were corrected using Cramer's V. Analysis of variance (ANOVA) was applied to compare the mortality and sporulation induced by $B$. bassiana and $M$. anisopliae on $S$. frugiperda larvae. Means were separated using the 
Table 1 Endophytic colonization of Beauveria bassiana and Metarhizium anisopliae in maize plant tissues

\begin{tabular}{|c|c|c|c|c|}
\hline \multirow{2}{*}{$\begin{array}{l}\text { Plant } \\
\text { tissue }\end{array}$} & \multicolumn{2}{|c|}{ Beauveria bassiana } & \multicolumn{2}{|c|}{ Metarhizium anisopliae } \\
\hline & $\overline{\text { Mean } \pm \text { SE }}$ & $\begin{array}{l}\text { Fungal } \\
\text { colonization (\%) }\end{array}$ & $\overline{\text { Mean } \pm \text { SE }}$ & $\begin{array}{l}\text { Fungal } \\
\text { colonization (\%) }\end{array}$ \\
\hline Roots & $25 \pm 0.25 a$ & 62.5 & $32 \pm 0.29$ & 73.5 \\
\hline Stems & $5 \pm 0.65 c$ & 12.5 & $0 \pm 0.00$ & 0 \\
\hline Leaves & $10 \pm 0.29 b$ & 25.0 & $0 \pm 0.00$ & 0 \\
\hline
\end{tabular}

Means followed by different lowercase letters in the same column differ statically by the chi-square test $\left(p^{<} 0.05\right)$ SE standard error

Tukey DHS test. Chi-square, ANOVA, and LSD tests were run using STATGRAPHICS Plus 5.1 (Manugistics Inc.) with significance level of 0.05 .

\section{Results and discussion}

\section{Endophytic colonization of B. bassiana and M. anisopliae} on maize plant tissues

The EPF, B. bassiana and M. anisopliae, resulted positive for endophytic colonization of maize plant tissues. B. bassiana colonized roots, stems, and leaves of maize plants. However, a high occurrence $\left(\chi^{2}=5.06, \mathrm{df}=2, p=0.0014\right)$ of this fungus was obtained in roots than leaves and stems with $25 \pm 0.25,10 \pm 0.29$, and $5 \pm 0.65$ isolations, respectively (Table 1 ). These results revealed that the $B$. bassiana colonization $(62.5 \%)$ occurred on the maize roots showing differences $\left(\mathrm{X}^{2}=2.25 \mathrm{df}=1, p=0.0001\right)$ with the $12.5 \%$ of stems colonized by this fungus (Table 1). M. anisopliae was greater $\left(\chi^{2}=42.67, \mathrm{df}=2, p=0.0001\right)$ acquired from roots, $32 \pm 0.29$ isolations, than from leaves and stems, where no fungal colonization was detected (Table 1 ).

The obtained results showed that B. bassiana was endophyticaly established on roots, stems, and leaves of maize plants. These findings are in accordance with the results obtained by Mahmood et al. (2019), who revealed that all inoculated maize plants in their experiment contained endophytic B. bassiana. In addition, the highest colonization levels were $(61 \%)$ in the oldest inoculated leaves and (19\%) in the youngest non-inoculated leaves indicating the movement of the endophyte inside plants. It has been shown that after a foliar spray of B. bassiana on maize plants the hyphae can penetrate inside the xylem and act as entophyte in leaves tissues (Wagner and Lewis 2000). However, the present study showed that $M$. anisopliae was only detected on roots. Besides, Pilz et al. (2011) demonstrated that $M$. anisopliae spores applied on maize leaves were able to survive for no longer than 3 days after application, whereas on the soil surface a high increase of fungus densities were found after treatments. Other studies have been demonstrated that $M$. anisopliae was commonly associated with plant roots (Keyser et al. 2015). Other experiments revealed that $B$. bassiana reached a higher colonization on leaves than roots of Sorghum bicolor (L.) Moench when the grains were treated by a formulation of this fungus (Tefera and Vidal 2009). This result suggested that the endophytic colonization of $B$. bassiana can vary with the

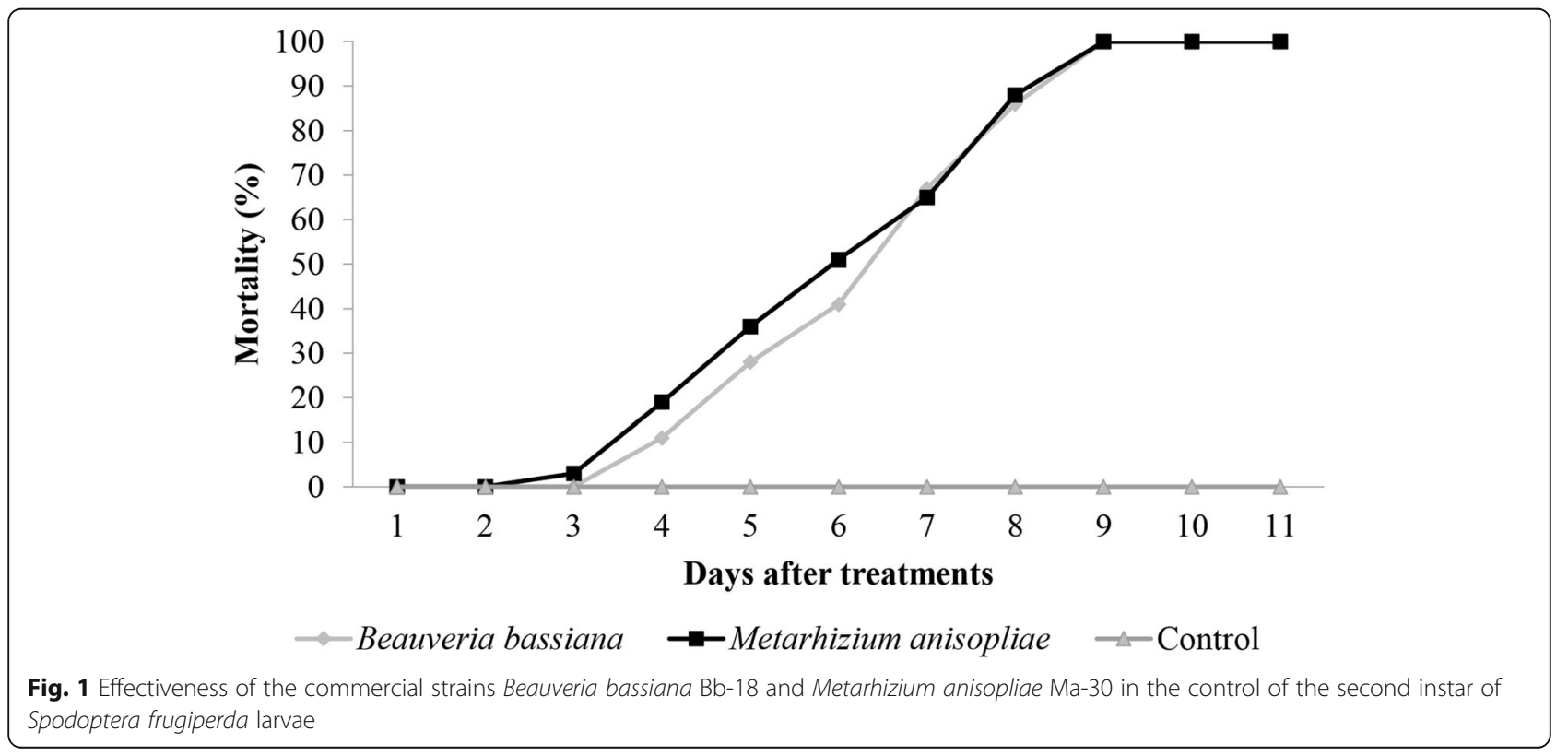




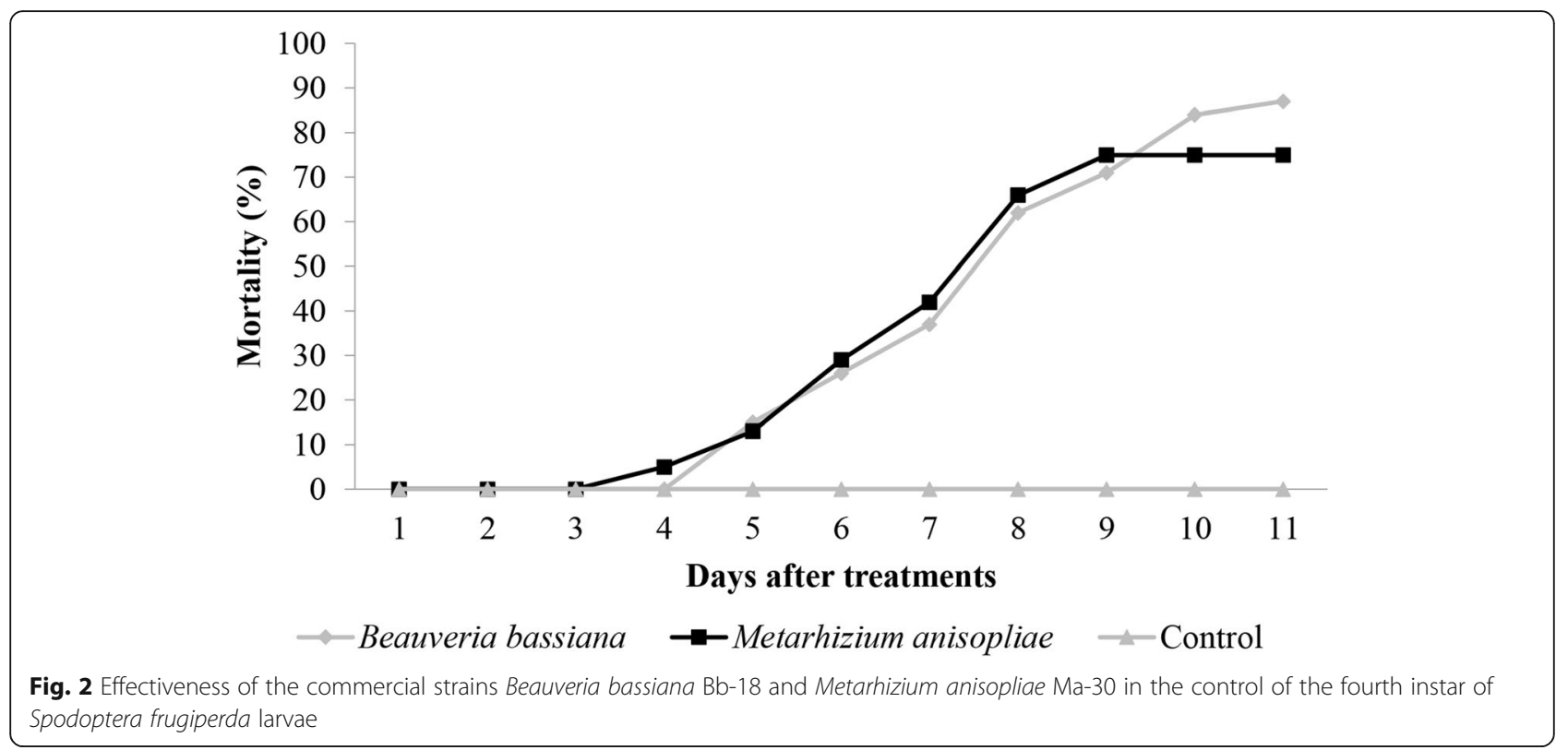

host plant part and the method used. Renuka et al. (2016) observed that stems of $Z$. mays were also colonized by $B$. bassiana; however, the availability and persistence on the plant tissues varied according to their age (high persistence in young tissues).

Despite several authors have demonstrated that $B$. bassiana as endophyte of maize, others have been revealed that after the inoculation of this EPF on maize seeds, no colonization of plant tissues was obtained (Tall and Meyling 2017).

\section{Effect of B. bassiana and M. anisopliae on S. frugiperda}

The survivorship experiments showed that B. bassiana started to kill larvae from the second instar of S. frugiperda on the fourth day after treatment, reaching $11 \%$ mortality rate. After that, mortality increased by this fungus reaching $100 \%$ mortality rate on ninth day after treatment. Meanwhile, $M$. anisopliae started its mortality on the third day after treatment with $19 \%$ larval mortality (Fig. 1).

At the fourth instar, the EPF $M$. anisopliae and $B$. bassiana started their mortality at third and fourth days after treatments, respectively. The mortality caused by $B$. bassiana was increased, reaching up to $87 \%$ on 11 th day after the application. However, the fungus could not kill
$100 \%$ of the larvae. On the other hand, M. anisopliae caused a maximum of $75 \%$ mortality rate (Fig. 2). The control treatment did not have any effect on second and fourth instars of $S$. frugiperda larvae.

No differences were detected $\left(p^{>} 0.05\right)$ on the mortality rates of $S$. frugiperda larvae treated with $B$. bassiana (19.45 \pm 0.23$)$ and M. anisopliae (19.36 \pm 0.28$)$. However, the sporulation level obtained with $M$. anisopliae $(9.1 \pm 0.20)$ was significantly higher than that obtained of B. bassiana (5.9 \pm 0.19$)$ (Table 2).

The results are in contrast with the findings obtained by Akutse et al. (2019), who demonstrated that B. bassiana ICIPE 676 caused moderate mortality of $30 \%$ to the second instar larvae of $S$. frugiperda, whereas $M$. anisopliae ICIPE 78, ICIPE 40, and ICIPE 20 caused egg mortality of 87,83 , and $79.5 \%$, respectively. This denotes that the virulence of these EPF may vary according to the strain origin.

Studies conducted to compare the sporulation level of $B$. bassiana and $M$. anisopliae demonstrated that the effectiveness of $3 \mathrm{~B}$. bassiana strains was greater than the effect caused by $M$. anisopliae, when these EPF were applied on Spodoptera litura F. Furthermore, B. bassiana caused the best candidate related to virulence and germination rates, whereas the highest enzymatic activity

Table 2 Mortality and sporulation caused by Beauveria bassiana and Metarhizium anisopliae on Spodoptera frugiperda

\begin{tabular}{lllll}
\hline $\begin{array}{l}\text { Entomopathogenic } \\
\text { fungi }\end{array}$ & Mortality & & Sporulation \\
\cline { 2 - 5 } & Mean \pm SE & $\begin{array}{l}\text { Percentage } \\
(\%)\end{array}$ & $\begin{array}{c}\text { Mean } \pm \text { SE } \\
(\%)\end{array}$ & 31.00 \\
\hline $\begin{array}{llll}\text { Beauveria bassiana } \\
\text { Metarhizium anisopliae }\end{array}$ & $19.45 \pm 0.23 \mathrm{a}$ & 95.20 & $5.9 \pm 0.19 \mathrm{~b}$ & \\
\hline
\end{tabular}

Means followed by different lowercase letters in the same column differ statically by the Tukey DHS test $\left(p^{<} 0.05\right)$ 
was resulted by the use of $M$. anisopliae (Petlamul and Prasertsan 2015).

Generally, several studies have been conducted to evaluate the effect of $B$. bassiana against lepidopteran species, but the effect of $M$. anisopliae on S. frugiperda larvae has been less reported and the present research constitute an advance in this regard.

Although there were no differences between the mortality produced by B. bassiana and M. anisopliae on $S$. frugiperda larvae, the sporulation rate was higher in the case of M. anisopliae than in B. bassiana. The EPF $M$. anisopliae had the ability to reach a $52.8 \%$ of sporulation on cadavers of $S$. frugiperda at 3 days after the mortality (Ibarra-Aparicio et al. 2005).

This result is important because the sporulation of the EPF from its host means the formation of a new source of inoculum for the infection of new populations of insect pests. Therefore, the fungus that shows the highest percentage of sporulation is more likely to be disseminated by biotic and abiotic agents.

\section{Conclusion}

The present study indicated that B. bassiana and M. anisopliae occurred as endophytes in maize plant parts, mainly in root tissues. Further, it highlights the importance of these EPF as potential biological control agents of $S$. frugiperda in maize fields in Cuba. These results suggest that the EPF studies could contribute to sustainable pest management of maize production.

\section{Abbreviations \\ BBCH: Phonological development stages of plants from Biologische Bundesanstalt Bundessortenamt und CHemische Industrie; df: Degrees of freedom; DHS: Honestly significant difference; EPF: Entomopathogenic fungi; L16:D8: $16 \mathrm{~h}$ of light and $8 \mathrm{~h}$ of dark; LSD: Least significant difference; $p: p$ value; RH: Relative humidity; SDA: Sabouraud Dextrose Agar; SE: Standard error; $x^{2}$ : Chi square}

\section{Acknowledgements}

We thank Universidad Central "Marta Abreu" de Las Villas for supplying the commercial strains B. bassiana Bb-18 and M. anisopliaeMa-30.

\section{Authors' contributions}

YR and OP conceived and designed the experiment. YR, AT, and JJ executed the experiment. YR and $\mathrm{OP}$ analyzed the data. YR, OP, AT, and JJ wrote and reviewed the manuscript. All authors read and approved the final manuscript.

\section{Funding}

Not applicable

\section{Availability of data and materials}

The datasets used and/or analyzed during the current study are available from the corresponding author on reasonable request.

\section{Ethics approval and consent to participate}

This manuscript is in accordance with the guide for authors available on the journal's website. Also, this work has not been published previously and is approved by all authors and host authorities

Consent for publication

All authors approve to publication.

\section{Competing interests}

The authors declare that they have no competing interests.

\section{Author details}

'Departamento de Agronomía, Universidad Central "Marta Abreu" de Las Villas, Carretera a Camajuaní km 5.5, 54830 Santa Clara, CP, Cuba.

2Departamento de Biología, Universidad Central "Marta Abreu" de Las Villas, Carretera a Camajuaní km 5.5, 54830 Santa Clara, CP, Cuba. ${ }^{3}$ Centro de Investigaciones Agropecuarias, Universidad Central "Marta Abreu" de Las Villas, Carretera a Camajuaní km 5.5, 54830 Santa Clara, CP, Cuba.

Received: 4 December 2019 Accepted: 19 February 2020

Published online: 02 March 2020

\section{References}

Akutse KS, Kimemia JW, Ekesi S, Khamis FM, Ombura OL, Subramanian S (2019) Ovicidal effects of entomopathogenic fungal isolates on the invasive fall armyworm Spodoptera frugiperda (Lepidoptera: Noctuidae). J Appl Entomol. https://doi.org/10.1111/jen.12634

Berón C, Salerno G (2006) Characterization of Bacillus thuringiensis isolates from Argentina that are potentially useful in insect pest control. BioControl 51: 779-794

Braga Maia J, Andrade G, Lopes R, Lasmar O, Santos M (2013) Effects of insecticides used in corn on immature stages of Trichogramma atopovirilia (Hymenoptera: Trichogrammatidae). Rev Colomb Entomol 39:205-210

Chacón-Castro Y, Garita-Rojas C, Vaglio-Cedeño C, Villalba-Veásquez V (2009) Desarrollo de una metodología de crianza en laboratorio del gusano cogollero del maíz Spodoptera frugiperda (Smith) (Lepidoptera: Noctuidae) como posible hospedante de insectos biocontroladores de interés agrícola. Tecnología en Marcha 22:28-37

Douglas G, Enkerly J, Goettel M (2012) Laboratory techniques used for entomopathogenic fungi: Hypocreales. In: Lacey LA (ed) Manual of Techniques in Invertebrate Pathology, 2nd edn. Academic Press, San Diego, pp 189-253

Hajek A, St Leger R (1994) Interactions between fungal pathogens and insect hosts. Annu Rev Entomol 39:293-322

Ibarra-Aparicio G, Moya-Raygoza G, Berlanga-Padilla A (2005) Efecto de Beauveria bassiana y Metarhizium ansopliae sobre la chicharrita del maíz (Dalbulus maydis) (Delong y Wolcott, 1923) (Hemiptera: Cicadellidae). Folia Entomol Mex 44:1-6

Keyser C, De Fine Licht H, Steinwender B, Meyling N (2015) Diversity within the entomopathogenic fungal species Metarhizium flavoviride associated with agricultural crops in Denmark. BMC Microbiol 15:249

Mahmood Z, Steenberg T, Mahmood K, Labouriau R, Kristersen M (2019) Endophytic Beauveria bassiana in maize effects survival and fecundity of the aphid Sitobion avenae. Biol Control. https://doi.org/10.1016/j.biocontrol.2019. 104017

Meier U (2001) Growth stages of mono-and dicotyledonous plants. BBCH Monograph. Ed. 2. Federal Biological Research Centre for Agriculture and Forestry, Germany, p 158

Petlamul W, Prasertsan P (2015) Evaluation of strains of Metarhizium anisopliae and Beauveria bassiana against Spodoptera litura on the basis of their virulence, germination rate, conidia production, radial growth and enzyme activity. Mycobiology 40:111-116

Pilz C, Enkerli J, Wegensteiner R, Keller S (2011) Establishment and persistence of the entomopathogenic fungus Metarhizium anisopliae in maize fields. J Appl Entomol 135:393-403

Pogue M (2002) A world revision of the genus Spodoptera Gueneé (Lepidoptera: Noctuidae). Memoirs Am Entomol Soc 43:1-201

Renuka S, Ramanujam B, Poornesha B (2016) Endophytic ability of different isolates of entomopathogenic fungi Beauveria bassiana (Balsamo) Vuillemin in stem and leaf tissues of maize (Zea mays L.). Indian J Microbiol 56:126-133

Tall S, Meyling N (2017) Probiotics for plants? Growth promotion by the entomopathogenic fungus Beauveria bassiana depends on nutrient availability. Microb Ecol 76:1002-1008

Tefera T, Vidal S (2009) Effect of inoculation method and plant growth medium on endophytic colonization of sorghum by the entomopathogenic fungus Beauveria bassiana. Bio Control 54:663-669

Vega F (2008) Insect pathology and fungal endophytes. J Invertebr Pathol 90: $277-279$ 
Virla E, Alvarez A, Loto F, Pera M, Baigorí M (2008) Fall armyworm strains (Lepidoptera: Noctuidae) in Argentina, their associate host plants and response to different mortality factors in laboratory. Fla Entomol 91:63-69 Wagner B, Lewis L (2000) Colonization of corn, Zea mays, by the entomopathogenic fungus Beauveria bassiana. Appl Environ Microbiol 66: 3468-3473

\section{Publisher's Note}

Springer Nature remains neutral with regard to jurisdictional claims in published maps and institutional affiliations.

Submit your manuscript to a SpringerOpen ${ }^{\circ}$ journal and benefit from:

- Convenient online submission

- Rigorous peer review

- Open access: articles freely available online

- High visibility within the field

- Retaining the copyright to your article

Submit your next manuscript at $\boldsymbol{\wedge}$ springeropen.com 